\title{
Do Iran's Buy-Back Service Contracts Lead to Optimal Production? The Case of Soroosh and Nowrooz ${ }^{1}$
}

\author{
Abbas Ghandi ${ }^{a}$ C.-Y. Cynthia Lin ${ }^{b}$ \\ ${ }^{\mathrm{a}}$ Institute of Transportation Studies, University of California at Davis, One Shields Avenue, \\ Davis, CA 95616, United States. Email: aghandi@ucdavis.edu. \\ ${ }^{\mathrm{b}}$ Agricultural and Resource Economics, University of California at Davis, One Shields Avenue, \\ Davis, CA 95616, United States. Email: cclin@primal.ucdavis.edu
}

December 8, 2011

\begin{abstract}
We model the dynamically optimal oil production on Iran's offshore Soroosh and Nowrooz fields, which have been developed by Shell Exploration through a buy-back service contract. In particular, we examine the National Iranian Oil Company’s (NIOC) actual and contractual oil production behavior and compare it to the production profile that would have been optimal under the conditions of the contract. We find that the contract's production profile is different from optimal production profile for most discount rates, and that the NIOC's actual behavior is inefficient- its production rates have not maximized profits. Because the NIOC’s objective is purported to be maximizing cumulative production instead of the present discounted value of the entire stream of profits, we also compare the NIOC's behavior to the production profile that would maximize cumulative production. We find that even though what the contract dictates comes close to maximizing cumulative production, the NIOC has not been achieving its own objective of maximizing cumulative production.
\end{abstract}

Keywords: dynamic optimal oil production, buy-back service contract, National Iranian Oil Company production behavior 


\section{Introduction}

The International Energy Agency projects a significant increase in world oil demand from the current level of 84.6 million barrels per day to 105.2 million barrels per day in 2030 (International Energy Agency [IEA], 2009). Meeting 2030 demand requires significant investment in oil production and oil transport infrastructure. Most of the investment will be in OPEC countries’ vast proven and recoverable reserves which, by 2030, will increase the OPEC share of world oil production from the current level of $44 \%$ to $52 \%{ }^{2}$

OPEC’s increasing share of production reinforces the importance of understanding production decisions and, in a more general context, OPEC countries’ energy policies. Among the OPEC members, Iran, with 137.6 billion barrels of proven oil reserves, is the second-largest oil producer and exporter after Saudi Arabia. Iran also holds the second-largest natural gas reserves after Russia. ${ }^{3}$

Iran’s centerpiece of energy policies, enforced by the National Iranian Oil Company (NIOC), has been structured on buy-back service contracts. The NIOC has persistently used buyback service contracts as almost the only framework for developing Iran’s oil and natural gas fields. A buy-back service contract is defined as a contract between the National Iranian Oil Company and an International Oil Company (IOC), in which the IOC agrees to develop an oil or natural gas field and then to hand the field over to the NIOC once production starts. The IOC's annual repayment rates are based on specific percentages of the production of the field and an agreed-upon rate of return.

By using a buy-back service contract framework, the NIOC has been able to meet Iran’s strict constitutional provisions restricting foreign oil companies’ involvement in Iranian oil and natural gas projects, since in the contract the IOC must hand the field back to the NIOC for 
production. Also this policy has enabled the NIOC to benefit from the IOCs' technical and financial capabilities, since the IOC is responsible for developing the field (Van Groenendaal \& Mazraati, 2006).

A few studies have discussed Iran’s buy-back service contracts. Bindemann (1999) describes Iran’s buy-back as a combination of a production sharing and a service contract with more characteristics of a service contract. Marcel (2006) reviews terms of buy-back contracts with an emphasis on their differences with production sharing agreements.

Shiravi and Ebrahimi (2006) give an interesting review of the history of service contracts in Iran from 1974. The study also discusses the terms of a buy-back service contract as well as the risk factors for an IOC. Van Groenendaal and Mazraati (2006) discuss risk factors in buyback service contracts in more detail by using an empirical model. Their model of cash flow, based on one buy-back service contract in the South Pars natural gas field, shows the possibility of a large reduction in the IOC's rate of return if oil prices drop below a certain threshold or if there is a delay in construction.

As a state-owned company, the NIOC has the responsibility of satisfying the objectives of the Iranian government, both economic and non-economic. As a consequence, the NIOC pursues revenue maximizing objectives as well as some other non-economic objectives, including maintaining Iran’s low domestic prices for fossil fuels ${ }^{4}$ and maintaining a high employment rate of Iranian nationals. On the other hand, the company’s structure and its autonomy from direct supervision by the Iranian parliament have enabled the company to gain some leverage on other Iranian institutions and branches of government. This has given the company the ability to pursue economic-based objectives to some degree (Brumberg \& Ahram, 2007). 
In this study we focus on Iran's buy-back service contracts, and we investigate the optimality of the production decisions that result from them. Using dynamic optimization, we model the dynamically optimal production on one of the buy-back service contracts, Soroosh and Nowrooz.

In general, Powell (1990) categorizes models of OPEC countries’ oil production decisions into models using intertemporal optimization and models using simulation-based approaches to model the behavior of decision makers. Ramcharran (2002) has a more general categorization of the approaches in the studies of production behavior which includes the theory of nonrenewable resources, game theory, simulation, industrial economics, and economic efficiency. As mentioned first in both studies, the intertemporal (dynamic) optimization, which is based on Hotelling's (1931) model of nonrenewable resource extraction, is probably the most common tool in studying oil production behavior.

There are also engineering-based production decision models. The engineering models’ goal is to maximize the cumulative production on a field (Gao et al., 2009). But as Ruth and Cleveland (1993) argue, while most economic models of US oil supply and demand interactions do not consider physical and engineering characteristics, engineering models lack economic considerations as well. One exception is Gao et al. (2009) which includes engineering characteristics by enforcing inequality constraints in the dynamic profit maximization problem faced by the producer of a large Saudi Arabian oil field.

In case of the NIOC, apart from general objectives of the company that were discussed above, the company seeks a cumulative production maximizing policy ${ }^{5}$ to some extent for each field, based on engineering studies of the fields. In this study, a dynamic optimization ${ }^{6}$ model $^{-}$ based on Hotelling (1931) is used to find extraction profile that maximizes the present 
discounted value of the entire stream of per-period net profits subject to constraints. Through the constraints, we also consider engineering characteristics of the fields of the study. These engineering considerations are based on what have been defined as the maximum and minimum levels of production in a buy-back service contract as well as feasibility ${ }^{7}$ in the level of difference of two consecutive periods' production levels. We also model the optimal production if the producer were to maximize cumulative production, as the NIOC purports to do.

The basic Hotelling theory of nonrenewable resource extraction suggests an increasing trend for the shadow price of the resource over time. But a number of studies have shown evidence of other trends for the real world prices (Krautkraemer, 1998; Lin, 2009; Lin et al., 2009; Lin and Wagner, 2007). These studies have put forth several factors that contribute to the basic Hotelling's failure of explaining the real world prices, including the basic Hotelling's assumption of independence of extraction cost and remaining stock. In this study, we have used an expanded version of the basic Hotelling model by considering what is known as "stock effect.”

A “stock effect” refers to a more realistic assumption of dependence of extraction cost on stock of reserve remaining or cumulative extracted resource. This assumption is reasonable since due to deeper level of resource and/or lower pressure in the reservoir, extraction in each period will increase the cost of extraction in the next periods. Moreover, in an oil field for example, cheaper grades are expected to be extracted first due to lower extraction cost. Hence, as more reserve is extracted and only the more expensive grades remain, the cost of extraction increases. (Lin, 2009; Lin et al., 2009; Lin and Wagner, 2007). Stock effects have also been studied by others as well (see e.g., Farzin, 1992; Slade, 1982; Hanson, 1980; Levhari and Liviatan, 1977; Solow and Wan, 1976). 
In this study, the outcomes of the Soroosh and Nowrooz buy-back service contract have been compared with the outcomes of two dynamic optimization scenarios: one in which the present discounted value of the entire stream of profits is maximized, and one in which cumulative production is maximized. This approach allows us to avoid having to choose a particular policy objective. Instead, we study both possible policy preferences. When comparing the actual and contractual production to the production profile under profit maximization, we find that the contract does not dictate the optimal production profile for the most discount rates and that the NIOC is not behaving efficiently. Because the NIOC's objective is purported to be maximizing cumulative production instead of the present discounted value of the entire stream of profits, we also compare the NIOC's behavior to the production profile that would maximize cumulative production. We find that even though what the contract dictates comes close to maximizing cumulative production, the NIOC has not been achieving its own objective of maximizing cumulative production.

The organization of this paper is as follows. Section two presents the model and methodology. Section three describes the data. In section four, results are presented followed by conclusion and discussion in section five.

\section{Model}

\subsection{Soroosh and Nowrooz buy-back service contract}

In order to study Iran’s production decisions, we give particular attention to Iran’s unique situation in using buy-back service contracts in developing its oil and natural gas fields. We therefore base our model of optimal production on characteristics of a buy-back service contract for the chosen fields of study: Soroosh and Nowrooz. 
As two producing neighboring fields from 1960s, Soroosh and Nowrooz production platforms were damaged during Iraq-Iran war in 1980s. In 1999, following the implementation of the buy-back framework by the NIOC, Shell signed its only contract with Iran after the revolution to develop these once producing fields. The objective was to reach 190,000 barrels of cumulative production with initial capital cost ceiling around $\$ 800 \mathrm{M}^{8}$

Similar to the buy-back service contracts signed between 1995 and 2003, the Soroosh and Nowrooz contract (signed in 1999) also lacks Iran’s Central Bank guarantee on repayments to IOCs. This is a common feature of Iran's second type of buy-back service contract as opposed to the first version introduced in earlier years (Shiravi \& Ebrahimi, 2006).

On the other hand, this contract has the main features of other buy-backs including similar ownership and operatorship rights of the fields and the crude produced as well as the same method of cash flow calculations. Based on a key term in these contracts, once production of the fields of the contract starts, the NIOC takes over the operation of the field (Van Groenendaal \& Mazraati, 2006). This means that in addition to ownership rights of the crude produced, and in contrast to production sharing agreements, the NIOC is the operator of the developed fields in the buy-back framework.

The buy-back service contract cash flow calculation is based on the formula below (Van Groenendaal \& Mazraati, 2006):

$$
N P V_{I O C}=\sum_{t=0}^{T} \frac{-(\text { Capex })_{t}}{\left(1+r_{I O C}\right)}+\sum_{i=T+1}^{I} \frac{(\text { Bank Charges })_{i}+(\text { Remuneration })_{i}+(\text { Repayment })_{i}}{\left(1+r_{I O C}\right)^{i}}=0
$$

where $N P V$ stands for the net present value of the cash flow until time period $T$; $r$ represents rate of return; Capex (capital cost expenditures) is the total capital cost occurred in the development period; Bank Charges (financing cost) denotes the expenses on the money borrowed for 
development including the compound interests; Remuneration is extra payments (rewards) for the IOC’s services including carrying on engineering, procurement and construction activities along with financing the project and technology transfer; and Repayment is the fraction of the borrowings that will be repaid in each period by the NIOC.

Two separate mechanisms are enforced in the buy-back service contract cash flow. These two mechanisms serve two different purposes. In the negotiation phase (first mechanism), Capex (capital cost expenditures), Bank Charges and Repayments are known. The goal is to agree on a rate of return and Remuneration for the IOC. Repayments calculations are based on an agreed upon fixed oil price and money equivalent of a share of the produced crude for the IOC.

But once the production starts (second mechanism), the goal is to keep the rate of return from exceeding the agreed upon rate of return while the actual oil price changes. At this stage, Capex (capital cost expenditures), Bank Charges and Remuneration are known.

For this paper, we have used the cash flow calculation method to define some of the constraints used when modeling the optimal production decisions of the Soroosh and Nowrooz oil fields.

\subsection{Soroosh and Nowrooz Optimal Control Problem}

Buy-back service contracts are long-term development projects involving exhaustible natural resources such as oil and natural gas. For the NIOC, a company which should seek a profit-maximizing policy, the best outcome is to maximize the profit of each field of a buy-back service contract over time. Hotelling's (1931) theory of non-renewable extraction is to model such optimization over time using dynamic optimization. Developed by Bellman (1957), dynamic programming is defined as a numerical solution for dynamic optimization problems. In 
Bellman’s (1957) notations, state variables describe physical condition of a system. There are also choices that should be made on decision variables in such a way that maximizes an objective function as a function of state variables. These choices have effects on determining state variables next periods as well. In other words, the goal is to find an optimal policy ${ }^{9}$ to maximize the objective function. In this case, the NIOC’s optimal control problem for the Soroosh and Nowrooz fields would be to choose an extraction profile $Q_{t}$ to maximize the present discounted value of the entire stream of per-period net profit, given initial stock $s_{0}$ and the relationship between extraction and stock remaining, and subject to the non-negativity constraints of extraction and stock remaining as well as two additional constraints of cost greater than its fixed value and cumulative production not exceeding the initial reserve. In order to account for buyback specific features as well as engineering limitations, we add three additional constraints: a maximum production cap, which is based on each field's field-specific geological constraint; ${ }^{10}$ a minimum production limit, which is based on the terms of the contract; and a production feasibility restriction. ${ }^{11}$ Mathematically, NIOC's discrete-time finite-horizon optimal control problem can be written as the following:

$$
\operatorname{Max}_{\left\{Q_{t}\right\}} \sum_{t=0}^{T} \beta^{t}\left\{P_{t} * Q_{t}-C\left(S_{t}, Q_{t}\right)\right\}
$$

subject to

$$
\begin{gathered}
Q_{t} \geq 0 \\
S_{t} \geq 0 \\
S_{0}=S_{0} \\
S_{t+1}-S_{t}=-Q_{t} \\
\sum_{t=0}^{T} Q_{t} \leq s_{0} \\
C\left(S_{t}, Q_{t}\right) \geq c_{0} \\
Q_{t} \leq Q_{\max } \\
Q_{t} \geq Q_{\min } \\
A B S\left(Q_{t}-Q_{t-1}\right) \leq Q_{f},
\end{gathered}
$$


where $S_{t}$ is the state variable (stock of oil remaining in the ground); $s_{0}$ is the initial stock of oil in the ground, which is known; $Q_{t}$ is the control variable (extraction rate); $C\left(S_{t}, Q_{t}\right)$ is the cost function with $c_{0}$ as its fixed value; and $\beta$ is discount factor. Based on terms of contract, $Q_{\max }$ is $100,000 \mathrm{~b} / \mathrm{d}$ and 90,000 b/d for Soroosh and Nowrooz respectively; $Q_{\min }$ is determined in each period based on terms of the contract according to which up to $60 \%$ of the revenue ${ }^{12}$ of the period could be allocated to calculate the minimum production requirements for the IOC (Shell) share of crude; $Q_{f}$, which is the minimum value possible for the absolute value of the difference between the production in two consecutive periods, is set at $10,000 \mathrm{~b} / \mathrm{d}^{13}$

Also the notation $S_{t+1}-S_{t}=-Q_{t}$ in the constraints of optimal control problem asserts that in each period, to calculate the stock of oil remaining in the ground, annual production of the last period is subtracted from last period's state variable (stock of oil in the ground). Or in other words, this period stock of oil is equal to the last period stock of oil minus last year's production.

For each of the two fields, there is an exogenous price path $P_{t}$ based on the Energy Information Administration’s Reference price projection in several years. In fact, one novelty of the study is to account for the fact that at different points of time, there are different price estimates available.

To solve this dynamic optimization problem numerically, we formulate it using the following Bellman equation (Bellman, 1957):

$$
V\left(S_{t}\right)=\operatorname{Max}_{\left\{Q_{t}\right.}\left\{P_{t} * Q_{t}-C\left(S_{t}, Q_{t}\right)+\beta\left(V\left(S_{t+1}\right)\right)\right\}
$$

where $V\left(S_{t}\right)$ is the value function which is defined as a function of state variable, and it yields maximum amount of the objective function at time period $t$. In order to find this value, the optimal policy function, which is an optimal choice of extraction (control), considering stock in 
the ground (state) in time $t$, should be computed (Judd, 1998). Among possible solutions for the Bellman equation, we have used numerical backward induction. ${ }^{14}$

\subsection{Cost Function}

In general, estimating a field specific cost function was out of scope of this study. In addition, cost data for the fields of the study were not available. In fact, it seems that even the NIOC might not have perfect assessment of such cost analysis. ${ }^{15}$ As a result and based on the resource extraction literature, we use the cost function that was estimated by Chakravorty et al. (1997), and also used by Lin (2009) and Lin et al. (2009). Chakravorty et al.’s (1997) cost function, as a function of cumulative extraction, has been estimated using East-West Center Energy Program extraction cost data of several world energy resources. In its marginal form their cost function which best fits data is the following: ${ }^{16}$

$$
\frac{\partial C\left(S_{0}-S_{t}, Q_{t}\right)}{\partial Q_{t}}=c_{1} e^{c_{2}\left(S_{0}-S_{t}\right)}
$$

where $c_{1}=1.02899$ and $c_{2}=0.00125868$, where the reserves are in barrels and cost is in dollars per day.

The cost function's exponential dependence on reserve remaining depicts the assumption of "stock effects" which suggests that more extraction will increase the extraction cost in future. This happens through the relation between the extraction and reserve remaining. More extraction will decrease the reserve remaining which subsequently will increase the term $S_{0}-S_{t}$ in the exponential part of the cost function. The parameter $c_{2}$ shows the degree of the relationship between remaining reserve and extraction cost.

The above marginal form implies a cost function as the following: 


$$
C\left(S_{0}-S_{t}, Q_{t}\right)=c_{1} e^{c_{2}\left(S_{0}-S_{t}\right)} Q_{t}+c_{0}
$$

Our cost function, which represents the cost of operation and not the finance cost, has variable and constant $\left(c_{0}\right)$ parts. The constant term $c_{0}$ is not an arbitrary choice in this model. Based on the EIA's estimate for the US domestic oil and gas field equipment and production operation cost (Energy Information Administration [EIA], 2007), an average fixed cost of operation has been calculated for Soroosh and Nowrooz oil fields separately. This is the only place that we use EIA cost estimates for the Gulf of Mexico.

The EIA's offshore cost data set has been sorted based on the depth of the wells, types of the platforms and whether the oil production is a primary or secondary operation. To be able to choose the closest category to Soroosh and Nowrooz oil fields, in Table 1, the main characteristics of Soroosh and Nowrooz have been listed separately.

Table 1: Soroosh and Nowrooz Characteristics

[Petroleum Engineering and Development Company]

\begin{tabular}{|l|l|l|}
\hline & Soroosh & Nowrooz \\
\hline Location & Offshore & Offshore \\
\hline $\begin{array}{l}\text { Nume of Contract } \\
\text { (Platform Type) }\end{array}$ & $\begin{array}{l}\text { Development } \\
\text { (Primary Oil } \\
\text { Production) }\end{array}$ & $\begin{array}{l}\text { Development } \\
\text { (Primary Oil } \\
\text { Production) }\end{array}$ \\
\hline Depth of the Wells & 10 & 17 \\
\hline
\end{tabular}

Since Soroosh and Nowrooz are two offshore oil fields with a development contract, the EIA's cost data for primary oil production in the Gulf of Mexico seems the closest to our fields of the study.

The EIA’s data set for the Gulf of Mexico contains 100, 300 and 600 feet well depth. Also it includes two types of platforms: 12 and 18 slots.

As listed in Table 1, maximum depth in the Persian Gulf is $90 \mathrm{~m}$ (256 ft). Based on the Iranian company's website in charge of the development operation of Soroosh and Nowrooz, 
Soroosh oil field has 10 vertical and horizontal wells while Nowrooz has 17 wells. Therefore, we can assume Soroosh in 12-slot platform category and Nowrooz in 18-slot category.

Even though the Annual Operating Cost's calculation is based on 11,000 barrels per day crude oil production per platform, since the size of the platform is part of the marginal cost and not fixed cost, we use the numbers for 11,000 barrels per day crude oil production per platform for both Soroosh and Nowrooz with 100,000 and 90,000 barrels per day respectively.

Among the cost items of EIA’s Annual Operating Cost data set for the Gulf of Mexico, we assume Labor, Supervision, Payroll Overhead, Food Expense, Administrative and Insurance as the items that the NIOC is supposed to consider even without any production in one period.

Table 2 below includes the associated numbers for each cost item for the year 2006.

Table 2: Based on EIA's Annual Operating Cost in the Gulf of Mexico

\begin{tabular}{|l|l|l|}
\hline Cost Items & 12-Slots Platform (\$) & 18-Slots Platform (\$) \\
\hline Labor & $1,062,700$ & $1,171,300$ \\
\hline Supervision & 159,400 & 175,700 \\
\hline Payroll Overhead & 488,800 & 538,800 \\
\hline Food Expense & 95,000 & 108,500 \\
\hline Administrative & 509,900 & 553,300 \\
\hline Insurance & 502,500 & 697,700 \\
\hline Total Annual Cost & $2,818,300$ & $3,245,300$ \\
\hline Average Daily Cost & 7,731 (\$/day) & 9,142 (\$day) \\
\hline
\end{tabular}

This approach with the above mentioned cost items suggests a fixed cost of $\$ 7,700$ per day for Soroosh (12-slot platform) and \$9,100 per day for Nowrooz (18-slot platform).

For robustness, we tried $\$ 7.7 \mathrm{~K} /$ day as the middle value for the constant term in the cost function as well as $\$ 77 \mathrm{~K} /$ day and $\$ 0.77 \mathrm{~K} /$ day as the high and low values. We find that the results are not sensitive to the choice of the fixed value of the cost function, and thus the optimal production paths are not sensitive to our use of EIA cost data from the Gulf of Mexico. 


\subsection{Year/Perspective Versions of the Model}

As mentioned earlier, our optimal production models require inputting exogenous price estimates which change each year. In order to account for the effects of such price estimate changes on the optimal production paths, we have defined three distinct year/perspective versions of the model for each of the two fields. And for each field, each year/perspective version uses its own price estimates available at the time. These versions are based on three significant years. As shown on Table 3 for Nowrooz, these years together mark three distinct phases of negotiations (before 1999), development (1999 to 2004 for Soroosh and 2005 for Nowrooz) and actual production until 2009. ${ }^{17}$ For the Soroosh field, we model the optimal production from the perspective of the years 1999, 2004, and 2009. For the Nowrooz field, we model the optimal production from the perspective of the years 1999, 2005 and 2009, as shown in Table 3.

Table 3: Nowrooz three model year/perspectives

\begin{tabular}{|c|c|c|c|}
\hline Phase & One & Two & Three \\
\hline Period & Until 1999 & $1999-2005$ & $2005-2009$ \\
\hline Contract S tatus & Negotiation & Development & Actual Production \\
\hline $\begin{array}{c}|c| \\
\text { Mhe year the price estimate } \\
\text { was formed }\end{array}$ & 1999 & 2005 & 2009 \\
\hline Last year of time horizon & 2020 & 2025 & 2030 \\
\hline
\end{tabular}

For each field, optimal production paths from the 1999 perspective are compared with the contractual path, which enables us to argue about the efficiency in contractual production decisions in 1999, since the contract was signed in 1999. Actual production on Soroosh and 
Nowrooz started in 2004 and 2005 respectively, which marks the end of development periods of the two fields. Therefore, by comparing the actual production of immediate years of exploitation with optimal production paths of the scenarios from the perspective of 2004 and 2005, optimal considerations in these years are discussed. Model versions from the perspective of 2009 for the two fields examine the optimality considerations in all the years of exploitation until 2009 based on information available in 2009.

In addition to the three above mentioned versions of the models, for each field and based on available information of 2010, we have also defined a fourth version. The 2010 perspective for each field is used to make recommendations on the optimal level of production from the present onwards. This approach could actually help the NIOC to reduce the degree of inefficiency by producing as close as possible to the optimal levels.

\section{Data}

In this study, we have used data which are specific to Iran's Soroosh and Nowrooz fields and their buy-back service contract. We believe that the data we have on Soroosh and Nowrooz are the most detailed and comprehensive one could possibly get. Data are used either directly in the model or indirectly to be compared with the outcomes of the model. Data used directly include price estimates, initial reserves $\operatorname{sizes}^{18}$ and discount rates. The indirect used data are actual and contractual production data. In what follows, first the direct used data are discussed which will be followed by a short description for the indirectly used data. 


\subsection{Fields' Specific Price Estimates}

For price estimates and in accordance with each field's year/perspective version of the model, we use an adjusted price estimate based on the EIA's Reference case price projection that was available the year on which the particular version of the model is based. That means that price estimates in this study are partly from the EIA and partly are based on the calibration we did as described below.

Iranian Crude price formulas are based on Brent prices, but future price projections are only available from the EIA. The EIA’s Annual Energy Outlook reports the average price of imported low-sulfur crude oil to US refiners as the world crude oil prices (Energy Information Administration [EIA], 2006a). Since the imported low-sulfur crude oil to US refiners is similar to WTI crude in characteristics (Energy Information Administration [EIA], 2009a), and since the Brent and the WTI are very similar, ${ }^{19}$ it is reasonable to assume the same price for the Brent, the WTI and the EIA’s imported low-sulfur crude oil price. We therefore use the EIA projected prices as representative of what the Brent prices would be in the future. Following Iranian crude prices formulas of 2008, the Soroosh and Nowrooz average Official Selling Prices have been adjusted by premia of 15.74 and 15.04 \$/barrel below Brent prices. We use these numbers to adjust Soroosh and Nowrooz price estimates with the EIA's price projections for the model versions of 2009 and 2010 for each field. ${ }^{20}$

For the model versions of 1999 and 2004 (2005 for Nowrooz), Soroosh and Nowrooz prices follow 10.74 and 10.04 \$/barrel premia respectively below the EIA’s World Oil Price projection. This is based on the fact that before 2006, EIA was reporting "World Oil Price” as its price estimates. The "World Oil Price” was based on volume-weighted average price of all crude oils imported into the United States over a specified period. Since this type of crude had similar characteristics with the OPEC Basket, its price was following a premium of 6 to 8 \$/barrel below 
West Texas Intermediate or 5 to 6 \$/barrel below Brent prices (Energy Information

Administration [EIA], 2006b). On the other hand, since we assumed the WTI and Brent are the same, the Soroosh and Nowrooz premia of 15.74 and 15.04 \$/barrel below Brent prices suggest that for the years before 2006, Soroosh and Nowrooz premia should be 10.74 and $10.04 \$$ /barrel below the EIA’s World Oil Price projection. ${ }^{21}$ This includes 1999 and 2004 (2005 for Nowrooz) versions of the models.

Figure 1 and Figure 2 graph the Soroosh and Nowrooz price projections used in this study. 


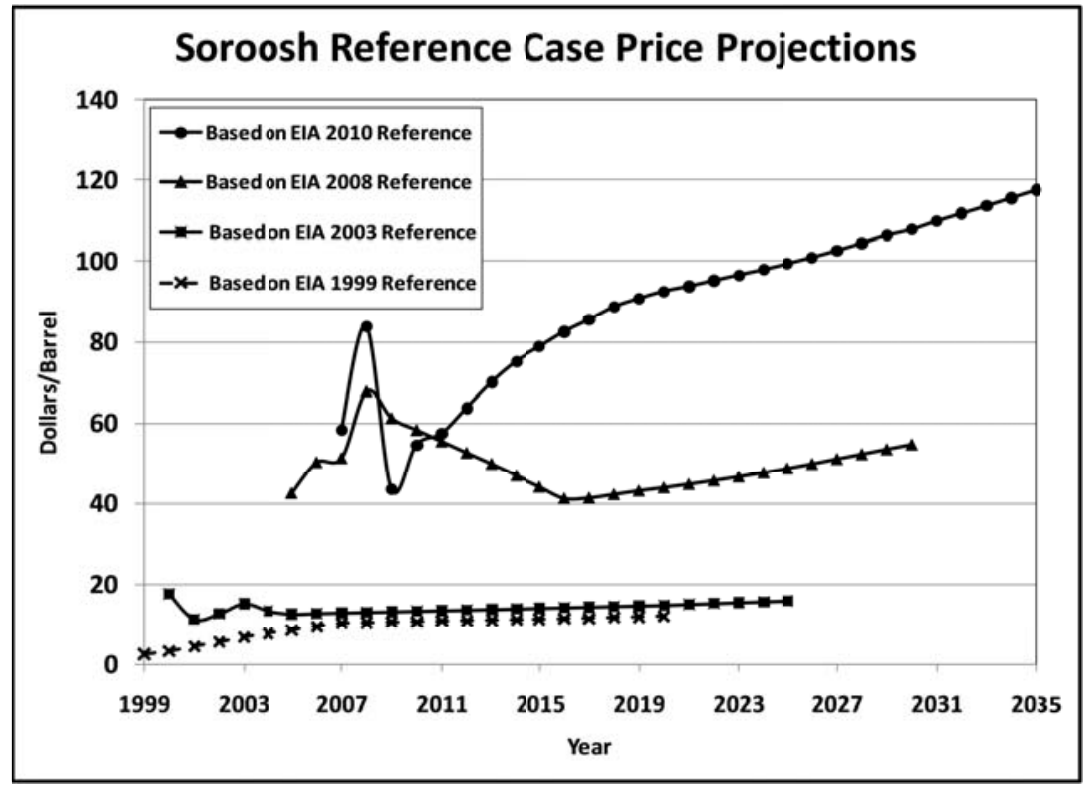

Figure 1 Soroosh Price Projections

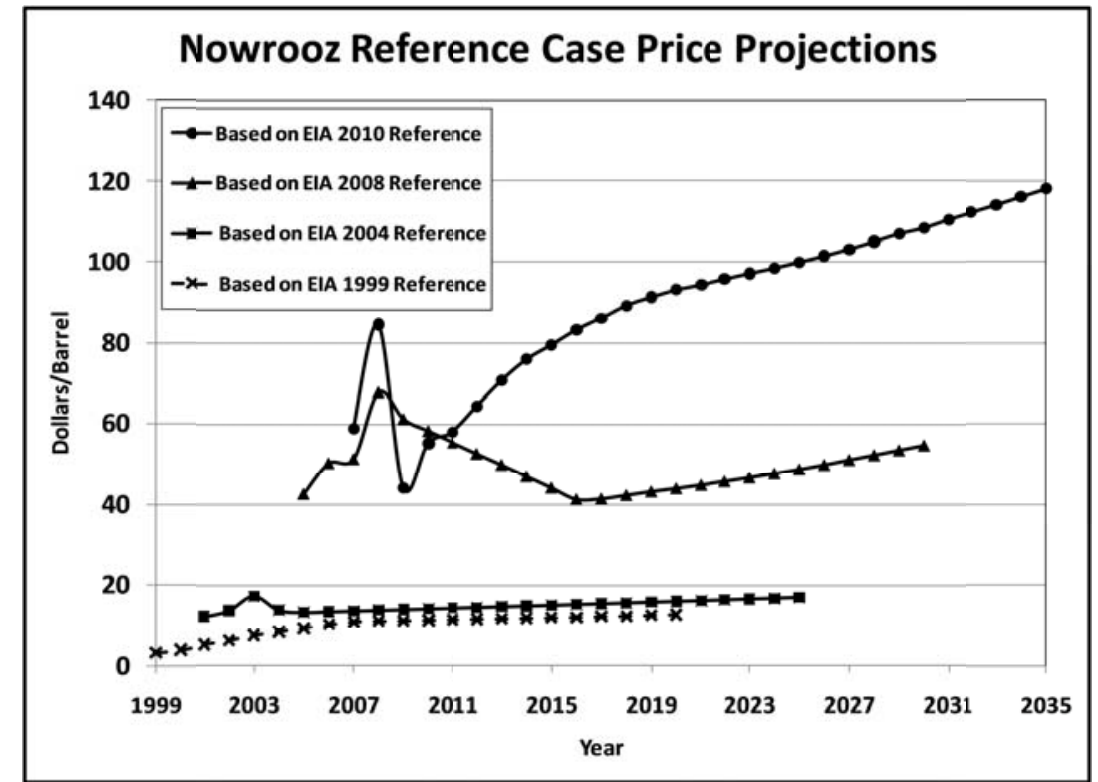

Figure 2 Nowrooz Price Projections 


\subsection{Discount Rates}

Dynamic optimization models also require a value for the discount factor which is determined by the choice of discount rate. It is not clear in reality what could have been the NIOC’s optimal choice of discount rate for the Soroosh and Nowrooz optimal production models. In order to avoid an arbitrary choice for discount rate, first we did a brief literature review of an appropriate choice of such discount rate. Adelman (1993) suggests that the discount rate should be $20 \%$ or higher for the countries with oil revenue as the most important source of government income. On the other hand, in the case of the Soroosh and Nowrooz buy-back service contract, the involvement of an IOC such as Shell might suggest lower discount rates as well. As a result, in order to avoid an arbitrary choice for discount rate, and to account for the effectiveness of the choice of discount rate on the optimal results, we did a sensitivity analysis on the discount rate by reporting the optimal production paths based on several discount rates ranging from $1 \%$ to $30 \%$.

\subsection{Fields' Specific Production Data}

In this study, the efficiency of the outcomes of this buy-back service contract is determined by comparing the optimal results with the actual and contractual production data. As for the actual data, we use fields' specific actual production data. For Soroosh, we use actual annual average daily production spanning from 2004 to 2009. For Nowrooz, we use actual annual average daily production spanning from 2005 to 2009. For the contractual data, we use each field's specific production forecast curve. Based on the engineering considerations, the production forecast curve for each field specifies the proposed production scenario until 2030 for 
the Soroosh and Nowrooz buy-back service contract. The production scenario includes annual average daily production levels based on pressure and other characteristics of each field. Overall, the actual and contractual production data were directly and specifically for Soroosh and Nowrooz.

\section{Results}

Figure 3 to Figure 10 graph the optimal production paths based on selected discount rates for the model versions of 1999, 2004 (2005), 2009 and 2010. 


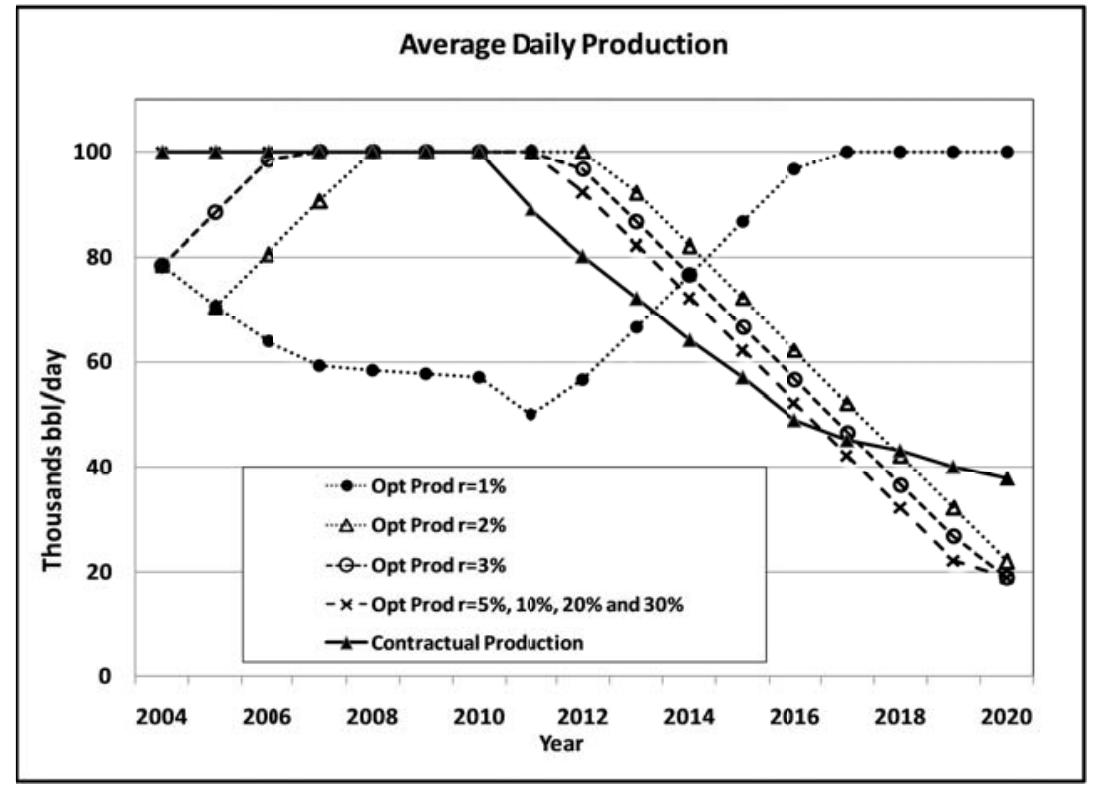

Figure 3. Optimal production for Soroosh when profit is maximized, from the perspective of the year 1999 for horizon 2020.

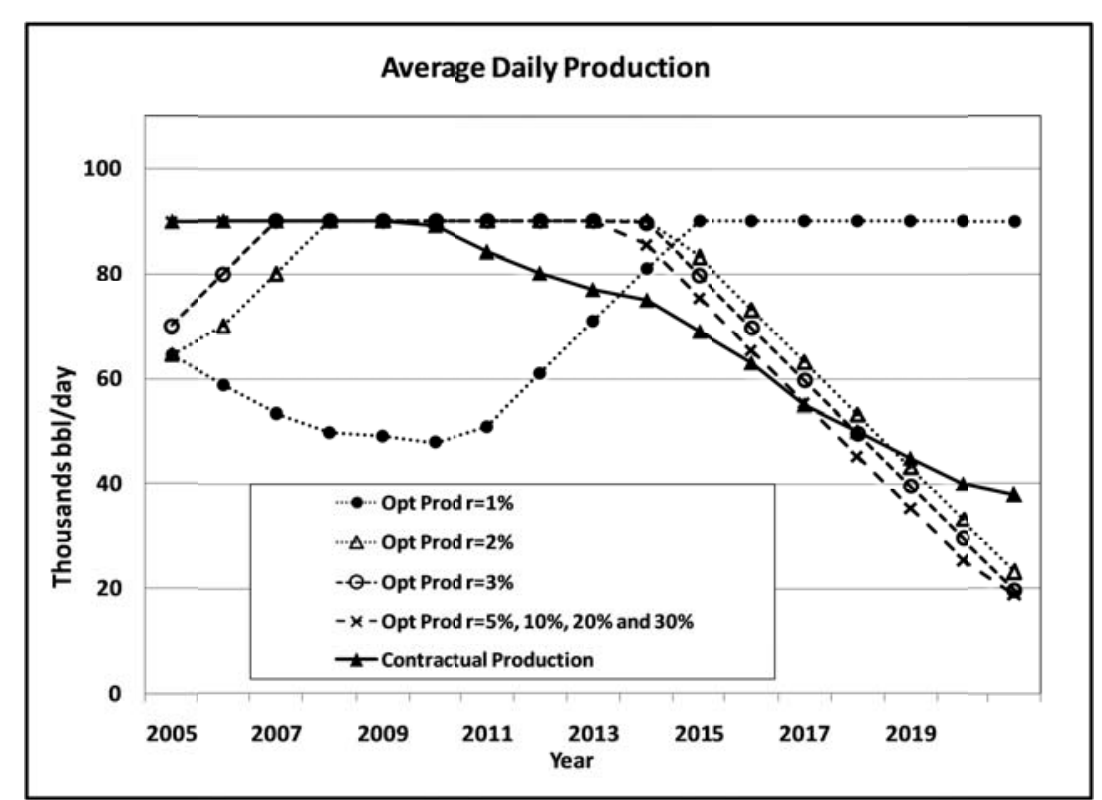

Figure 4. Optimal production for Nowrooz when profit is maximized, from the perspective of the year 1999 for horizon 2020. 
As shown on Figure 1 and Figure 2, the 1999 price estimates for the two fields are fairly stable and almost flat. As a result, the choice of discount rate is the primary factor affecting the results. For both fields, as shown on Figure 3 and Figure 4, optimal production paths of lower discount rates such as $1 \%$ have their peak production in the later years. Optimal production for discount rates such as 2 and 3\% start low and reach the peak in 2008 and 2007 respectively. But for discount rates higher than 5\%, our model of optimal production suggests peak production from the beginning and a sharp decline later from 2011 (2014 for Nowrooz). Another interesting finding is that the contractual production path does not coincide with any the optimal production paths. In general, the contractual production levels in the beginning years are higher than the optimal levels for discount rates of 1, 2 and 3\%. And they are the same as the levels for higher discount rates in the beginning years. For the later years, the contractual production levels are below the optimal levels for discount rates higher than $2 \%$ for most years except the last few years. $^{22}$

Similar to the 1999 versions, the Soroosh 2004 and Nowrooz 2005 year/perspective versions use stable and flat price projections which make the discount rate the main factor affecting the optimal results. As shown on Figure 5 and Figure 6, for higher discount rates in both fields, optimal models recommend producing at a peak in the beginning years followed by declining production paths in the later years. On the other hand, optimal production paths for a 1\% discount rate start in a declining path which should be reversed in 2013 (2016 for Nowrooz). These results clearly show that the NIOC did not choose the optimal production levels in either field for the two immediate years after the fields were handed back to them. 


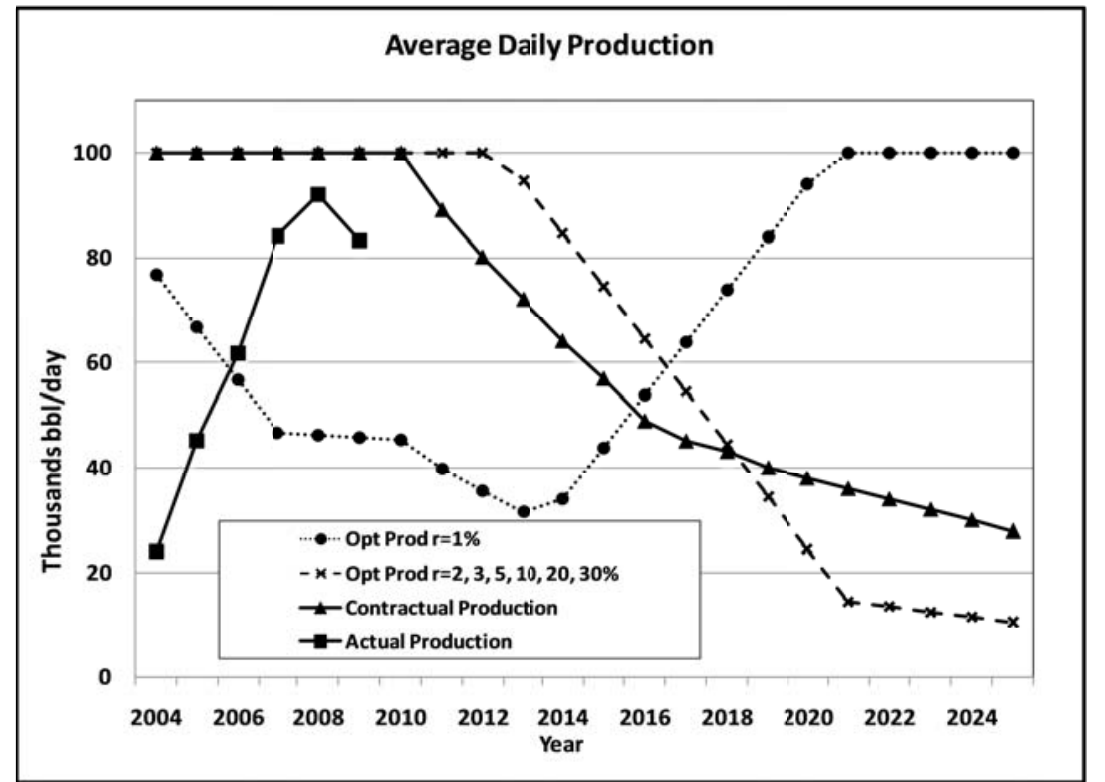

Figure 5. Optimal production for Soroosh when profit is maximized, from the perspective of the year 2004 for horizon 2025.

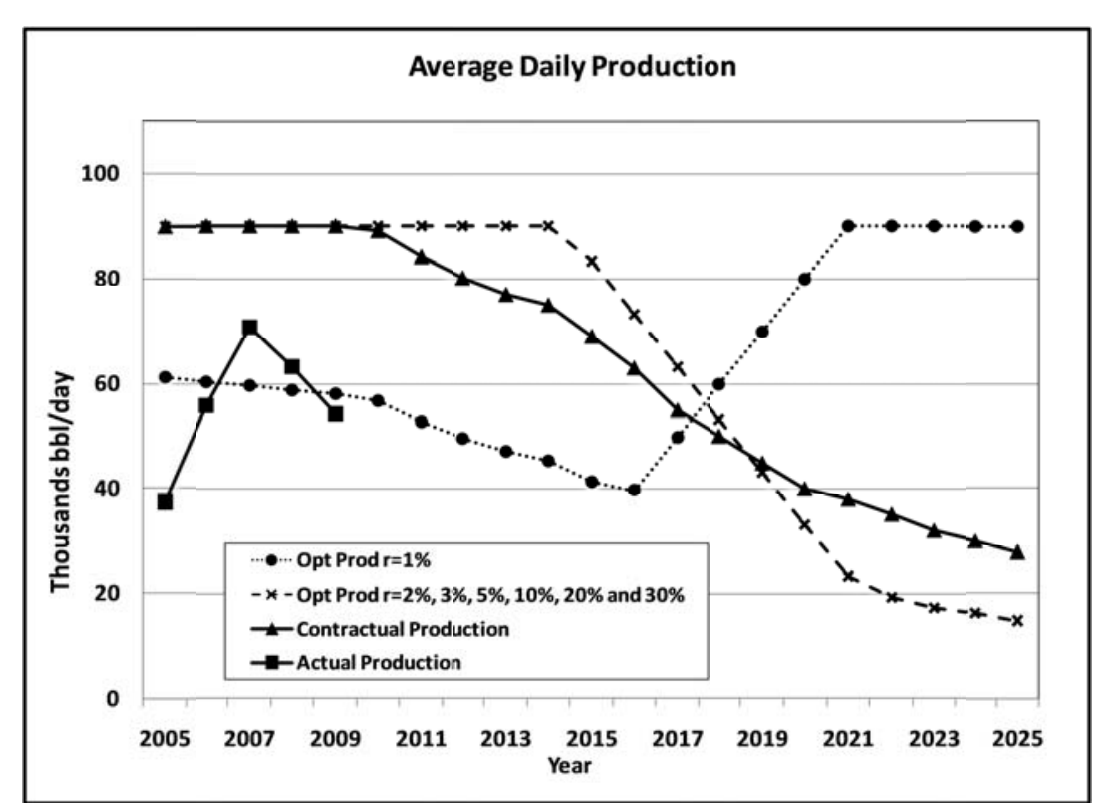

Figure 6. Optimal production for Nowrooz when profit is maximized, from the perspective of the year 2005 for horizon 2025. 
So far, stable price estimates have enabled an analysis of the effects of discount rates in the 1999 and 2004 (2005 for Nowrooz) versions of the optimal model. In these versions, for higher discount rates, optimal production levels are higher in the earlier years. And that is due to the fact that higher discount rates represent less importance placed on the future. Less importance placed on the future means that profits from future production are not as valued as much as profits from present production and as a result, production in the earlier years would be higher. By the same logic, in 1999 and 2004 (2005 for Nowrooz) versions, optimal production paths for lower discount rates start low in the beginning years.

On the other hand, the 2009 model versions of both fields use price estimates that are much higher than the previous ones. Therefore, as presented on Figure 7 and Figure 8, even for low discount rates, optimal models suggest production at or near the peak level in the beginning years. The 2009 results show that based on available information in 2009, the NIOC's actual production path has been far below all the optimal paths for any discount rates. This is a clear sign of economic inefficiency in the operation of the two fields of the study. 


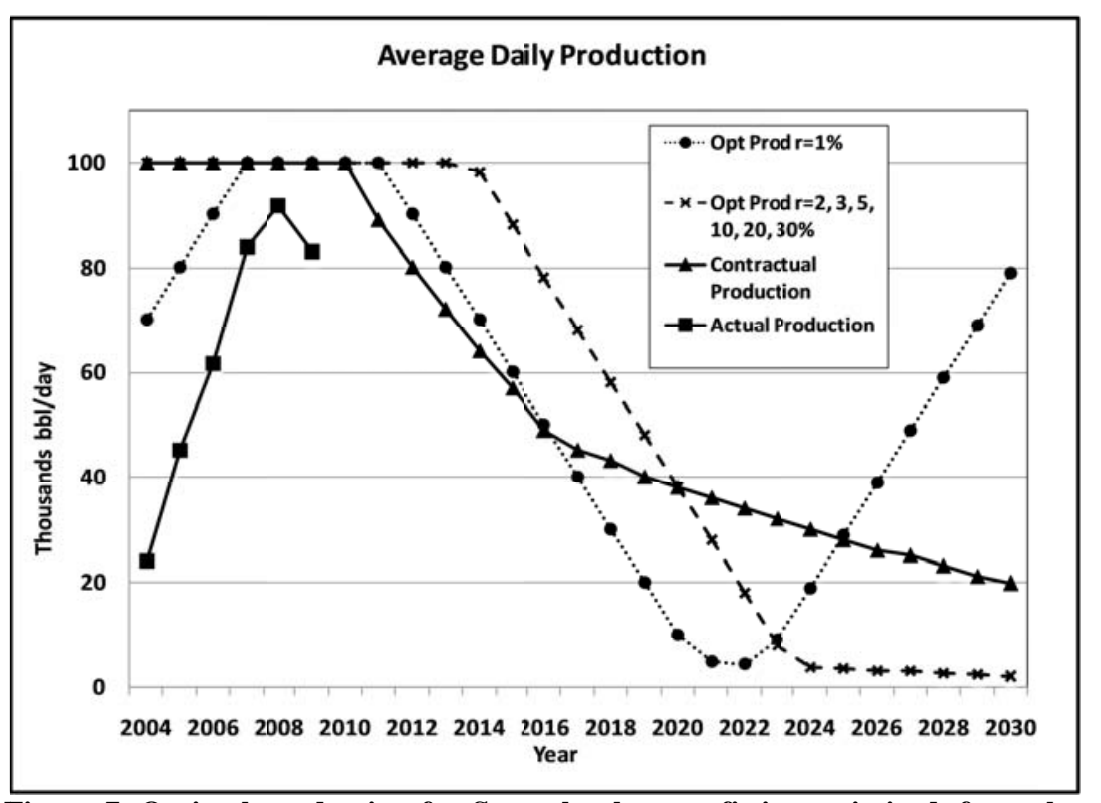

Figure 7. Optimal production for Soroosh when profit is maximized, from the perspective of the year 2009 for horizon 2030.

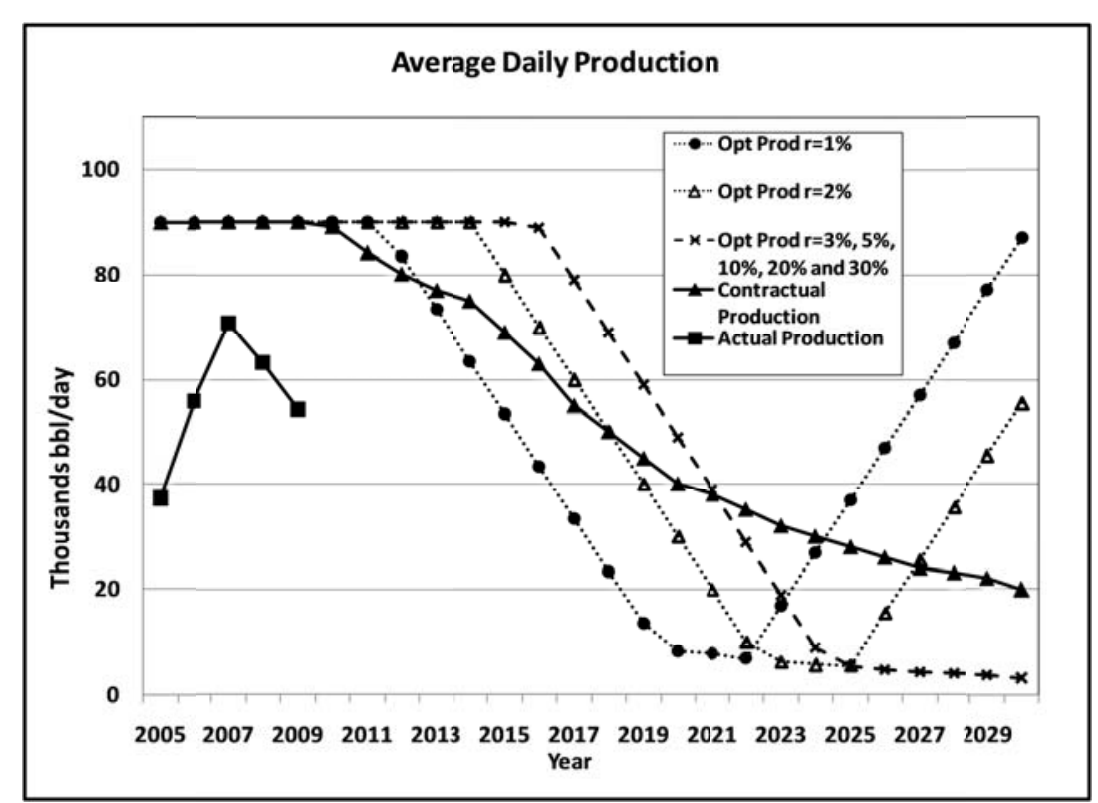

Figure 8. Optimal production for Nowrooz when profit is maximized, from the perspective of the year 2009 for horizon 2030 
Figure 9 presents the results of the Soroosh 2010 year/perspective version of the model, which represent the optimal production profile recommended for Soroosh from now into the future. For lower discount rates such as $1 \%$, the model suggests a peak production in the end years. For discount rates such as 2, 3 and 5\%, the optimal production paths start low and gradually ascent to the peak level. For these rates, the decline starts from 2023 (2\%), 2017(3\%) and 2015(5\%) respectively. For higher discount rates such as 10, 20 and 30\%, production starts at the peak with a sharp decline afterwards.

Similarly, Figure 10 presents the results of the Nowrooz 2010 year/perspective version of the model, which represent the optimal production profile recommended for Nowrooz from now into the future. For discount rates lower than 3\%, the optimal production paths start low and gradually ascend to the peak level. For a 1\% discount rate, the production stays at the peak, but for 2 and 3\%, the production declines again. For discount rates higher than 5\%, the model suggests production at a peak level followed by a gradual production decline starting in 2018. 


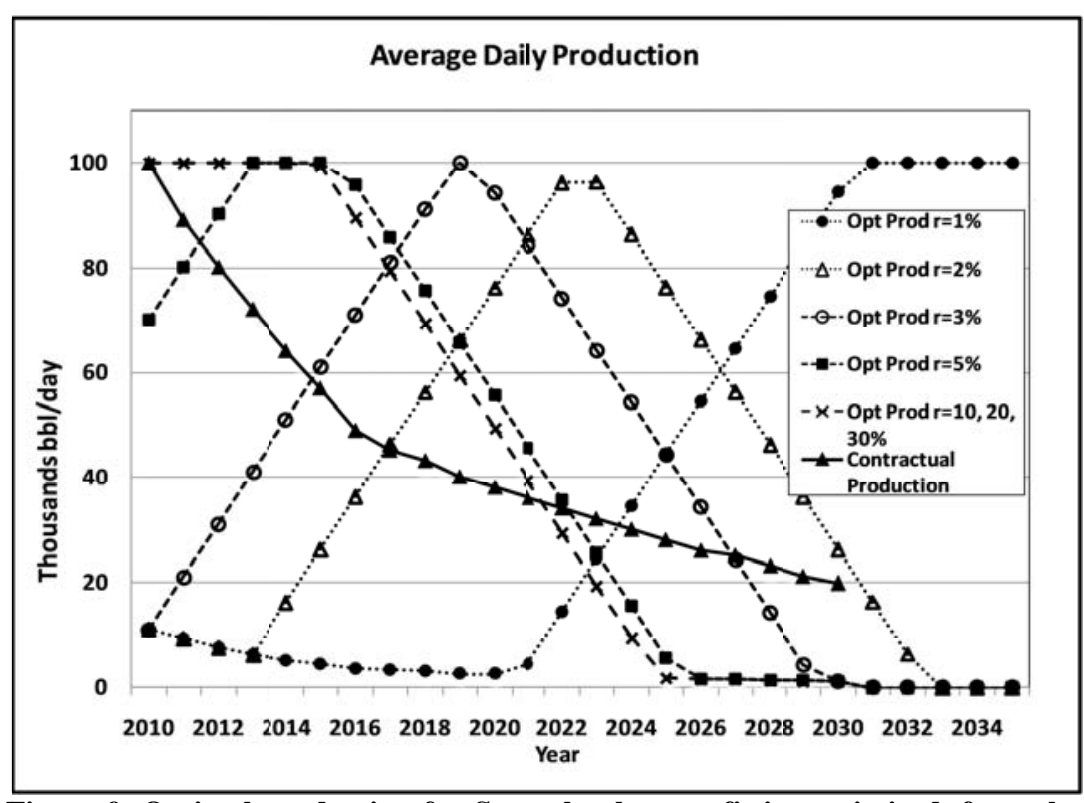

Figure 9. Optimal production for Soroosh when profit is maximized, from the perspective of the year 2010 for horizon 2035.

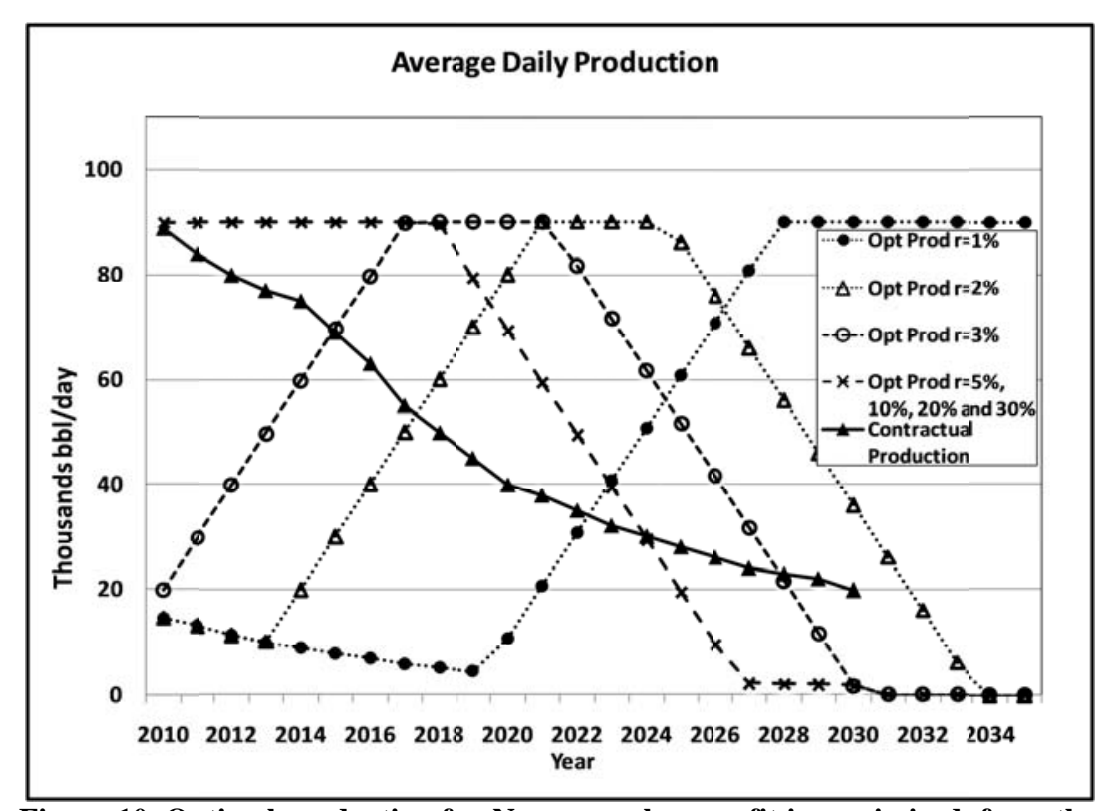

Figure 10. Optimal production for Nowrooz when profit is maximized, from the perspective of the year 2010 for horizon 2035. 
Because the NIOC's objective is purported to be maximizing cumulative production instead of the present discounted value of the entire stream of profits, we also compare the NIOC's behavior to the production profile that would maximize cumulative production. As

shown on Figure 11 and Figure 12, based on available information in $2009,{ }^{23}$ the production path that maximizes cumulative production is close to the contractual production path for each field for all the discount rates. This suggests that the contract does specify what is optimal to some extent, if the objective function is to maximize the cumulative production. However, even though what the contract dictates comes close to maximizing cumulative production, the NIOC has not been achieving its own objective of maximizing cumulative production on either of the two fields. 


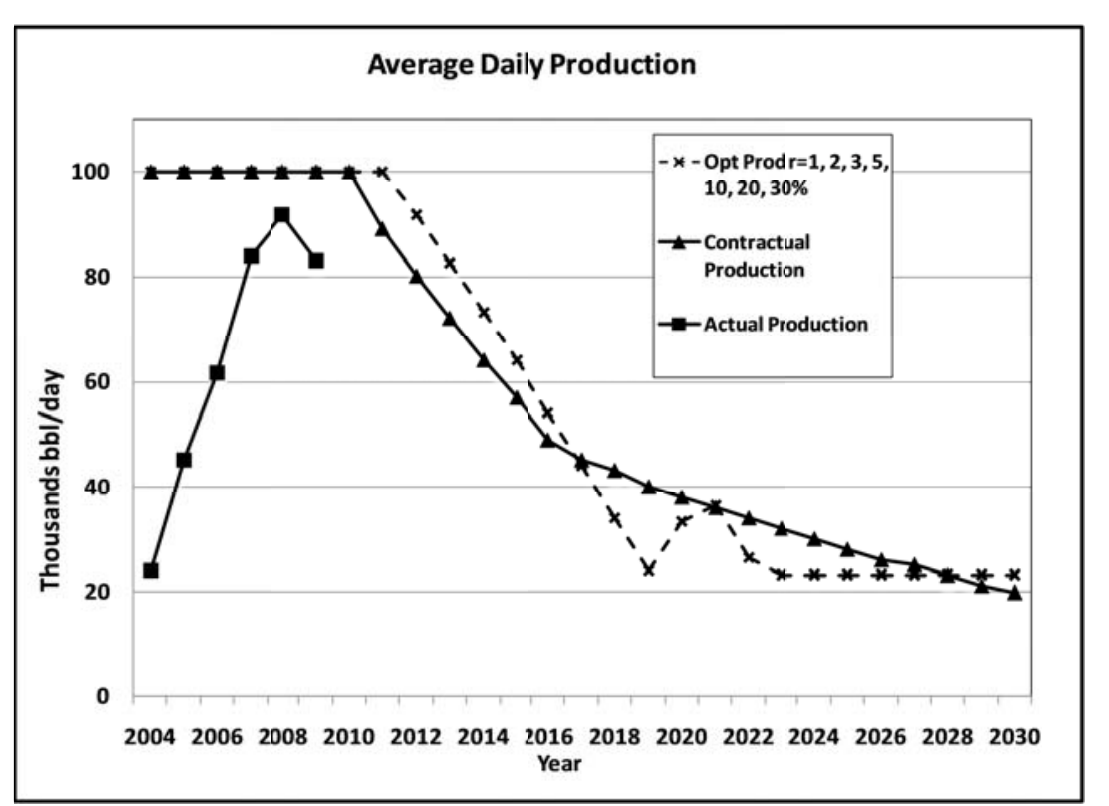

Figure 11. Optimal production for Soroosh when cumulative production is maximized, from the perspective of the year 2009 for horizon 2030.

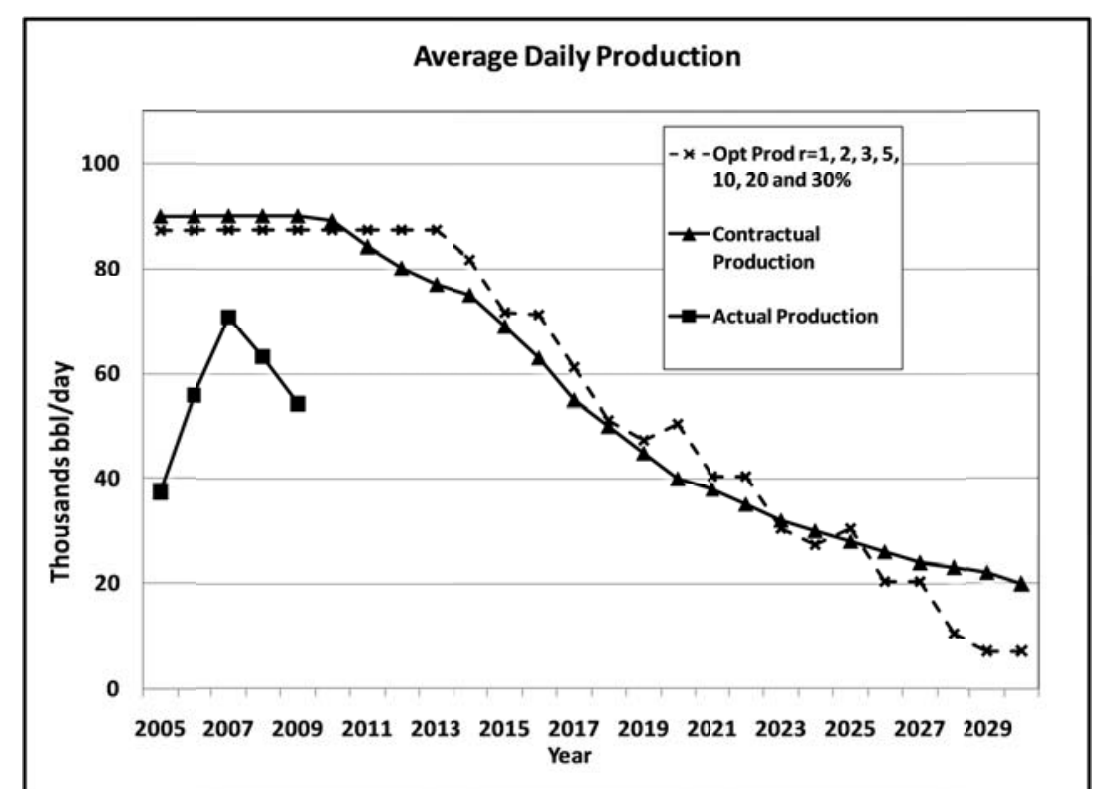

Figure 12. Optimal production for Nowrooz when cumulative production is maximized, from the perspective of the year 2009 for horizon 2030. 


\section{Conclusion and Discussion}

In this paper, we model optimal oil production in Iran’s Soroosh and Nowrooz fields, which have been developed by a buy-back service contract. Based on the results that were discussed earlier, we conclude that the NIOC is producing inefficiently, and the contract does not dictate what is optimal for most discount rates. However, if the objective is to maximize cumulative production rather than the present discounted value of the entire stream of profits, the contract's production path is close to optimal for each field. On the other hand, even though what the contract dictates comes close to maximizing cumulative production, the NIOC has not been achieving its own objective of maximizing cumulative production on either of the two fields. The low level of production could be partially explained by the terms of the contracts (the NIOC operatorship) and the crude share arrangements based on the cash flow calculations (marketing/customer issues) of the buy-back service contracts.

As mentioned before, based on a key term in these contracts, once production of the field of the contract starts, the field is handed over to the NIOC. However, the NIOC may lack the technology and expertise needed to determine the optimal production levels. ${ }^{24}$ Therefore, it is reasonable to consider the NIOC's operatorship as one possible explanation of the low level of actual production. Due to the severity of this issue, the NIOC has recently proposed a new amendment for its future buy-back service contracts requiring the IOC have NIOC personnel present in its operation during the development phase, so that the NIOC personnel might be trained more effectively to handle the operation afterwards (Mehrnews Agency, 2010). While it is not clear how the IOCs may react to this new constraint, the new amendment suggests that the 
NIOC acknowledges its failure in the operation of the developed fields including Soroosh and Nowrooz.

The crude share arrangements based on the cash flow calculations (marketing/customer issues) of the buy-back service contracts have also contributed to the low level of production. For the case of Soroosh and Nowrooz, in the recent years, oil prices were much higher than the contractual price, and as a result, the IOC's allocation of the crude had decreased significantly. A reduction in the IOC's share of the produced crude is the same as an increase in the NIOC's share of the produced crude.

With the extra crude in hand, the NIOC could follow three options. One was to sell Shell the extra crude at the new actual higher price. This could be done through a separate crude share arrangement, or maybe by recalculating the whole cash flow since this way Shell had the chance to recover its investment sooner than it expected. But price disputes with Shell prevented the NIOC from following this option. ${ }^{25}$ As a second option, the NIOC could use some domestic refineries to process the crude and either use the crude domestically or export the refined crude. But limitations on domestic refining capacity did not allow the NIOC to follow this option either. $^{26}$ The third option was to try to market the extra crude independently. Since this option was compatible with the NIOC's preference for finding separate niche markets for its initial share of Soroosh and Nowrooz (Middle East Economic Survey, 2005a), and because neither of the two other options were feasible, it is likely that the company pursued this third option. However, selling crude as heavy and sour as Soroosh and Nowrooz ${ }^{27}$ was difficult and time consuming. Moreover, limited storage facilities prevented the NIOC from maintaining the same rate of production while looking for customers. Therefore, at some point, the NIOC decided to reduce the production level and even temporarily shut down production until it could find customers 
(Middle East Economic Survey, 2005a). Thus, the crude share arrangements based on the cash flow calculations (marketing/customer issues) of the buy-back service contracts contributed to the low level of production.

These effects on the production levels are unique to the buy-back service contracts. That is because in other types of oil fiscal systems including production sharing contracts, the IOC is awarded more rights including ownership rights on percentages of the crude and/or operatorship rights on the developed field. The ownership rights would solve the marketing problem since both sides have time to do the marketing effectively, and they know their share of crude for a long period of time. In addition, the presence of the IOC on the developed field would increase the possibility of having the technology and expertise needed to determine the optimal production levels.

Thus, possible modifications of buy-back service contracts that may induce a more economically efficient outcome include awarding operatorship rights on the developed field and ownership rights on percentages of the crude produced. Having the IOC as the sole or joint operator of the field would help the NIOC to produce more economically efficiently and to train its personnel more effectively.

However, as mentioned before, the NIOC's main reason for using a buy-back framework was to be able to benefit from the IOCs' knowledge and investments in the country while complying with Iran's strict Constitutional restrictions on foreigners' involvements in the oil and natural gas sector. Since there is no clear sign of any fundamental change in the framework of oil and natural gas buy-back service contracts, awarding ownership rights based on percentages of the crude may not be possible. 
As another possible modification, the NIOC may need to be more flexible in selling the crude, for example by following a joint marketing strategy with the IOC. Such flexibility will allow the company to deal efficiently with the customer issue resulting from the unexpected higher volumes of crude in hand in situations when oil prices increase and the IOC's crude share declines. However, even after solving the customer issue, the NIOC might still not produce optimally with this contract or other buy-back projects, for example because it may lack the technology or expertise to determine the optimal production levels, or it may have non-economic considerations in its objective function.

The NIOC, as a national company, should increase transparency in its behavior. Transparency should include the actual and contractual production levels as well as the selling prices for the crude. The sensitivity of oil as a national treasure among Iranians requires a great deal of effort for any small changes in the contracts. Transparency will help the NIOC gain more public support for its efforts in partnership with the IOCs which subsequently could help enforce more fundamental modifications to buy-back service contracts.

While the main focus of this paper was on optimal considerations of the two fields until 2009, as shown on Figure 9 and Figure 10, Soroosh and Nowrooz 2010 versions present the production paths recommended for the future based on the choice of discount rate. These optimal production paths are based on current price estimates and reserve remaining in the ground following a few years of production. If, in this contract, the NIOC wanted to consider economic efficiency as its objective from this point forward, it could consider adopting our 2010 versions’ approach and methodology. ${ }^{28}$ We also showed that the contractual profile for each field does not dictate the optimal profile for most discount rates. Therefore, we recommend a modification in 
the current buy-back framework that allows for considering economic efficiency in planning the contractual profiles in new contracts.

In the end, it is important to mention that this study covers a period of time between 2000 and 2009 when the situation in Iran was not as complicated as it is today. As a result of the nuclear standoff and the disputed 2009 presidential election with the emergence of the Green Movement in Iran, the country suffers a worldwide financial isolation accompanied by a deep internal political crisis. The situation has slowed down or halted many Iranian oil and natural gas projects, and in fact from now on, examining a buy-back service contract or modeling the production decision in Iran require including broader issues. But still, this paper has a potential of huge impacts on policy including moving towards other types of contract or at least modifying the terms of the buy-back service contracts as well as considering economic optimality in the actual and contractual production decisions.

\section{References}

Adelman, M.A. (1993). Modelling World Oil Supply. The Energy Journal , 14, 1-32.

Bellman, R. (1957). Dynamic programming. Princeton University Press.

Bindemann, K. (1999). Production Sharing Agreements: An Economic Analysis. Oxford Institute for Energy Studies. Oxford Institute for Energy Studies.

Brumberg, D., \& Ahram, A.I. (2007). The National Iranian Oil Company in Iranian politics. The James A. Baker III Institute for Public Policy.

Chakravorty, U., Roumasset, J.A., \& Tse, K. (1997). Endogenous Substitution Among Energy Resources and Global Warming. Journal of Political Economy, 150, no. 6.

Energy Information Administration [EIA]. (2006a). Annual Energy Outlook 2006. Retrieved March 1, 2010, from http://www.eia.doe.gov/oiaf/archive/aeo06/pdf/0383(2006).pdf 
Energy Information Administration [EIA]. (2006b). Pricing Differences among Various Types of Crude Oil . (2006). Retrieved February 27, 2010 , from: http://tonto.eia.doe.gov/ask/crude_types1.html.

Energy Information Administration [EIA]. (2007). Oil and Gas Lease Equipment and Operating Costs 1988 Through 2006. Retrieved November 8, 2009, from http://www.eia.doe.gov/pub/oil_gas/natural_gas/data_publications/cost_indices_equipment_prod uction/current/coststudy.html.

Energy Information Administration [EIA]. (2009a). Annual Energy Outlook 2009. Retrieved March 1, 2010, from http://www.eia.doe.gov/oiaf/archive/aeo09/

Energy Information Administration [EIA]. (2009b). Annual Energy Review 2009. Retrieved November 12, 2010, from http://www.eia.doe.gov/aer/petro.html

Farzin, Y.H. (1992). The Time Path of Scarcity Rent in the Theory of Exhaustible Resources. The Economic Journal , 102 (413), 813-830.

Gao, W., Hartley, P.R., \& Sickles, R.C. (2009). Optimal dynamic production from a large oil field in Saudi Arabia. Empirical Economics , 37 (1), 153-184.

Hanson, D.A. (1980). Increasing Extraction Costs and Resource Prices: Some Further Results. The Bell Journal of Economics , 11 (1), 335-342.

Hotelling, H. (1931). The Economics of Exhaustible Resources. The Journal of Political Economy , 39 (2), 137-175.

International Energy Agency, [IEA]. (2009). World Energy Outlook 2009. Organisation for Economic Co-operation and Development OECD.

International Energy Agency, [IEA]. (2010). World Energy Outlook 2010. Organisation for Economic Co-operation and Development OECD.

Judd, K.L. (1998). Numerical Methods in Economics (Vol. 1). The MIT Press.

Krautkraemer, J.A. (1998). Nonrenewable Resource Scarcity. Journal of Economic Literature , 36 (4), 2065-2107.

Levhari, D., \& Liviatan, N. (1977). Notes on Hotelling's Economics of Exhaustible Resources. The Canadian Journal of Economics / Revue canadienne d'Economique , 10 (2), 177-192.

Lin, C.-Y.C. (2009). Insights from a Simple Hotelling Model of the World Oil Market. Natural Resources Research , 18 (1), 19-28.

Lin, C.-Y.C., \& Wagner, G. (2007). Steady-state growth in a Hotelling model of resource extraction. Journal of Environmental Economics and Management , 54 (1), 68-83. 
Lin, C.-Y.C., Meng, H., Ngai, T.Y., Oscherov, V., \& Zhu, Y.H. (2009). Hotelling Revisited: Oil Prices and Endogenous Technological Progress. Natural Resources Research , 18 (1), 29-38.

Marcel, V. (2006). Oil Titans National Oil Companies in the Middle East. Brookings Institution Press.

Mehrnews Agency. (2010, November 29). Details of Third Generation Oil Contracts. Interview with Payam Bathayi, the NIOC's Director of Legal and Contract Affairs, in Farsi. Tehran,

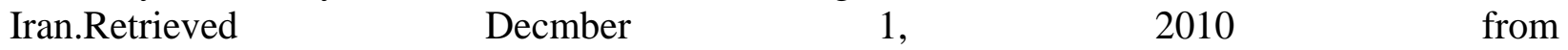
http://www.mehrnews.com/fa/newsdetail.aspx?NewsID=1200729

Middle East Economic Survey. (2005a, September 5). Nowruz Production Shut Down Temporarily by NIOC. A Weekly Review of Energy, Finanance and Politics .

Middle East Economic Survey. (2005b, August 1). Zanganeh Inaugurates Soroush/Nowruz Fields. A Weekly Review of Energy, Finanance and Politics .

Middle East Economic Survey. (2005c, September 5). NIOC Marketing Nowruz Crude Separately from Soroush. A Weekly Review of Energy, Finanance and Politics .

Petroleum Engineering and Development Company (PEDEC). Development of Soroosh and Nowrooz Oil Fields. Retrieved November 8, 2009, from: http://www.pedec.ir/projectdetail-fa15.html

Powell, S.G. (1990). The Target Capacity-Utilization Model of OPEC and the Dynamics of the World Oil Market. The Energy Journal , 11 (1), 27-64.

Ramcharran, H. (2002). Oil production responses to price changes: an empirical application of the competitive model to OPEC and non-OPEC countries. Energy Economics , 24 (2), 97-106.

Ruth, M., \& Cleveland, C.J. (1993). Nonlinear dynamic simulation of optimal depletion of crude oil in the lower 48 United States. Computers, Environment and Urban Systems , 17 (5), 425-435.

Shiravi, A., \& Ebrahimi, S.N. (2006). Exploration and development of Iran's oilfields through buyback. Natural Resources Forum , 30 (3), 199-206.

Slade, M.E. (1982). Trends in natural-resource commodity prices: An analysis of the time domain. Journal of Environmental Economics and Management , 9 (2), 122-137.

Solow, R.M., \& Wan, F.Y. (1976). Extraction Costs in the Theory of Exhaustible Resources. The Bell Journal of Economics , 7 (2), 359-370.

Van Groenendaal, W.J.H., \& Mazraati, M. (2006). A critical review of Iran's buyback contracts. Energy Policy, Volume 34, Issue 18, 3709-3718. 
${ }^{1}$ The authors would like to thank the Sustainable Transportation Energy Pathways (STEPS) Program at the University of California at Davis, Institute of Transportation Studies (ITS) for funding this project. This project benefited from comments and suggestions by participants at the STEPS 2008 and 2009 seminar series and poster sessions; the UK Energy Summer School 2009 poster session; and the International Energy Agency (IEA) 2010 High Noon Series seminar. In particular, we had helpful discussions with Lew Fulton of the IEA, Wayne Leighty of UC Davis-ITS and Didier Bougeard of TOTAL Business Development Iran. We also would like to acknowledge several National Iranian Oil Company (NIOC) staff for sharing data. All errors are our own.

2 This is close to the OPEC's peak share of production, which occurred in 1973, when OPEC production was 29.66 million barrels per day and the total world production was 55.68 million barrels per day. (Energy Information Administration [EIA], 2009b)

${ }^{3}$ Energy statistics for Iran were obtained from US Energy Information Administration Country Analysis Briefs.

${ }^{4}$ The International Energy Agency estimates that Iran’s policy of maintaining a low domestic price for fossil fuels costs the country $\$ 66$ billion annually. As of October 2011, however, the Iranian government has taken the initial steps in lifting its subsidies on electricity, natural gas, gasoline, diesel, kerosene, liquefied petroleum gas (LPG) and other oil derivatives. The generated revenue from such a change in policy will be partially redistributed among Iranian households. (International Energy Agency, [IEA], 2010) The new policy is part of a huge initiative by the Iranian government to eventually lift subsidies in all sectors of the economy.

${ }^{5}$ Personal communications with NIOC staff, September 2009.

${ }^{6}$ Optimization over time.

${ }^{7}$ Personal communication with Total Iran Business Team, May 2010.

${ }^{8}$ Information on Iran's Soroosh and Nowrooz contract were obtained from Iran’s Petroleum Engineering and Development Company, which is a subsidiary of the NIOC.

${ }^{9}$ A policy is “any rule for making decisions which yields an allowable sequence of decisions.” (Bellman, 1957, p. 82)

${ }^{10}$ Personal Communication with NIOC staff, September 2009.

${ }^{11}$ Without these additional constraints, dynamic optimization results in unrealistically high production for some years for some discount rates. 
${ }^{12}$ We consider revenue instead of profit since $60 \%$ revenue results in a more stringent minimum production constraint, and since our assumption does not affect the general shape of the trajectories.

${ }^{13}$ Personal communication with Total Iran Business Team, May 2010.

${ }^{14}$ In other words, starting with an initial guess, we compute the value function via backward iteration.

${ }^{15}$ Personal communication with NIOC staff, December 2007.

${ }^{16}$ Instead of cumulative stock extracted, we use stock of oil remaining in the ground $\left(\mathrm{S}_{\mathrm{t}}\right)$.

${ }^{17}$ This method also enables further discussion of the optimal considerations in production decisions of the NIOC's sub-companies in charge of each of the three phases.

${ }^{18}$ Based on the fields' specific geological information, each of the two fields has an initial recoverable reserve estimate below 600 million barrels of oil (personal communication with NIOC staff, September 2009).

${ }^{19}$ This is because 1 to 2 \$/barrel is the premium considered for WTI compared to Brent (Energy Information Administration [EIA], 2006b), and because the WTI and Brent crudes have similar characteristics: WTI has an API of 39.6 and is 0.24 percent sulfur, while Brent has an API of 38.3 and is 0.37 percent sulfur.

${ }^{20}$ This requires another simplifying assumption that the 2008 average premia are the same in the other years.

${ }^{21}$ This is from considering the lowest premium of 5 dollars per barrel below Brent price for the EIA's "World Oil Price”.

${ }^{22}$ The optimal production figures for Soroosh and Nowrooz when profit is maximized, from the perspective of the year of 1999, do not include the actual production path. That is because the actual production did not start until 2004 (2005 in Nowrooz), and because the model versions of the year 1999 are used to compare the contractual production with the optimal production paths.

${ }^{23}$ Analogous results hold for the other year/perspective versions for each field.

${ }^{24}$ Personal communications with NIOC staff, September 2009.

${ }^{25}$ Personal communications with NIOC staff, September 2009.

${ }^{26}$ This is based on news reports in the summer of 2005 that mention why the NIOC was thinking of upgrading a domestic refinery to process Soroosh and Nowrooz crude in Iran (Middle East Economic Survey, 2005b).

${ }^{27}$ Soroosh has an API of 18 and is 3.4 percent sulfur, and Nowooz has an API of 19 and is 3.5 percent sulfur (Middle East Economic Survey, 2005c). 
${ }^{28}$ In addition, the company should allow its sub-companies in charge of the operation of the developed fields to decide on the level of the production based on economic optimality. This requires allowing the sub-companies to decrease the production level if it is economically efficient to do so. Currently, the objective of maximizing cumulative production requires the sub-companies to produce as much as the engineering of the field allows them to produce in each period. As a result, in some periods, the NIOC may even produce higher than it should if it were to be economic efficient. 